\title{
Vieux - Le forum
}

n'3399

Karine Jardel, Jean-Yves Lelièvre et Pierre Mazure

\section{(2) OpenEdition}

\section{Journals}

Édition électronique

URL : http://journals.openedition.org/adlfi/17069

ISSN : 2114-0502

Éditeur

Ministère de la culture

Référence électronique

Karine Jardel, Jean-Yves Lelièvre et Pierre Mazure, «Vieux - Le forum », ADLFI. Archéologie de la France

- Informations [En ligne], Basse-Normandie, mis en ligne le 17 mars 2016, consulté le 30 avril 2019

URL : http://journals.openedition.org/adlfi/17069

Ce document a été généré automatiquement le 30 avril 2019

(C) Ministère de la Culture et de la Communication, CNRS 


\title{
Vieux - Le forum
}

n'3399

\author{
Karine Jardel, Jean-Yves Lelièvre et Pierre Mazure
}

Lien Atlas (MCC)

http://atlas.patrimoines.culture.fr/atlas/trunk/index.php?

ap_theme=DOM_2.01.02\&ap_bbox=-0.461;49.101;-0.423;49.125

1 La fouille programmée menée sur le forum antique d'Aregenua s'est déroulée durant les mois de juin, juillet et septembre 2013. Elle s'est concentrée sur les zones en bordure des bâtiments civiques et sur le bâtiment à abside accolé au nord-est de cet ensemble.

2 La présence sur le site d'une structure de protection de type "échafaudage parapluie ", communément utilisé dans les chantiers de restauration des monuments historiques, a conditionné l'emprise des sondages effectués, notamment sous cet édifice. En effet, posée sur le niveau de circulation actuel et lestée, la façade orientale de la structure repose sur l'emprise du bâtiment à abside qu'elle traverse sur toute sa longueur. Ainsi, au vu des questions de stabilité et de sécurité, la fouille a été conduite sur une large fenêtre couvrant le tiers ouest de l'édifice, complétée par un sondage, plus petit, au sud-est.

Le bâtiment à abside est un vaste édifice de 22,5 $\mathrm{m}$ de long et $17 \mathrm{~m}$ de large, fermé par un mur droit au nord (M 47), et un mur en arc de cercle au sud (M 25).

4 Ces murs viennent s'adosser contre deux constructions antérieures: le bâtiment comportant la curie et autres bureaux de l'administration à l'ouest et, à l'est, une imposante maçonnerie dont l'extension demeure inconnue. Le sol est formé d'un radier de calcaire émoussé sur lequel ne sont conservées que quelques lentilles de mortier jaune. Sur ce sol reposent d'imposants blocs de calcaire alignés selon un axe nord-sud, parallèlement aux murs de l'édifice. De 0,91 à 0,92 $\mathrm{m}$ de long sur 0,50 à 0,60 cm de large, quatre blocs sont disposés à 1,60 $\mathrm{m}$ du mur ouest M 21. Deux autres éléments en calcaire, de module semblable et d'alignement identique, ont été mis au jour dans le sondage effectué à l'est du bâtiment. À proximité immédiate de ces derniers, une fosse tardive recoupant l'ensemble des niveaux a livré plusieurs éléments de débitage de fûts et de 
bases de colonne, ainsi qu'un fragment de colonne composé d'un fût lisse et d'une base attique. L'hypothèse de soubassements d'une colonnade semble de fait vraisemblable.

Le deuxième état d'occupation est caractérisé par des modifications architecturales internes. L'entrecolonnement est comblé par un « muret » de pierres sèches, constitué de blocs de schiste et de calcaire grossièrement équarris (M 60). Cet aménagement forme les fondations d'une élévation en matériaux périssables. En parallèle, un épais remblai rehausse le niveau de circulation de plus de $30 \mathrm{~cm}$. Deux sols successifs viennent buter contre cette élévation en matériaux périssables.

6 Le remblai a livré un lot céramique hétérogène dont les éléments les plus récents datent de la fin $d u I^{e}$ ou du début du ${ }{ }^{e}{ }^{e} s$., ce qui situe la mise en place de ce nouvel aménagement intérieur avec des parois en matériaux périssables, à la même phase que les travaux d'embellissement engagés dans la curie (phase IIB).

7 Les opérations de fouille intervenant dans la partie méridionale de l'area ont permis de compléter, de préciser et de nuancer les données recueillies lors des campagnes 2008 et 2009. Elles ont été organisées au sein de deux sondages localisés, l'un à l'aplomb du mur M18, et l'autre à l'aplomb de la berme occidentale.

8 Une première constatation s'impose : les murs orientés est-ouest ( $\mathrm{M} 55, \mathrm{M} 56, \mathrm{M} 72$ ), qui avaient été découverts lors des campagnes précédentes et interprétés comme structurant les galeries et boutiques de la place publique du forum, ont été arasés très tôt dans ce secteur, vraisemblablement avant la phase II de l'occupation du site. Deux nouveaux murs orientés nord-sud ont été mis au jour, le premier, sous le mur M18, et le second à l'aplomb de la berme occidentale. Tous ces murs appartiennent donc à la phase I de l'occupation du site, structurant de petites pièces de dimensions semblables dont la fonction nous est encore inconnue. La fouille s'est interrompue sur le dernier niveau lié à la phase I (antérieure à la construction du forum) dont les vestiges évoquent l'aménagement d'un plancher. Ce niveau apparaissant fortement rubéfié et recouvert par des éléments de destruction témoigne, comme cela a pu être observé dans différentes pièces, d'un épisode d'incendie scellant la fin de l'occupation de l'édifice monumental antérieur au forum.

9 Les rares vestiges de la phase II conservés dans ce secteur consistent en plusieurs couches de remblais, visant à compenser les pendages présents entre les murs sous-jacents et l'intérieur des pièces qu'ils délimitaient, suivies de plusieurs niveaux de circulation. Les intersections des murs M 55, M 56, et M 68 ont quant à elles fait l'objet de remaniements qui pourraient être en rapport avec la mise en place de la galerie de façade occidentale du forum. 


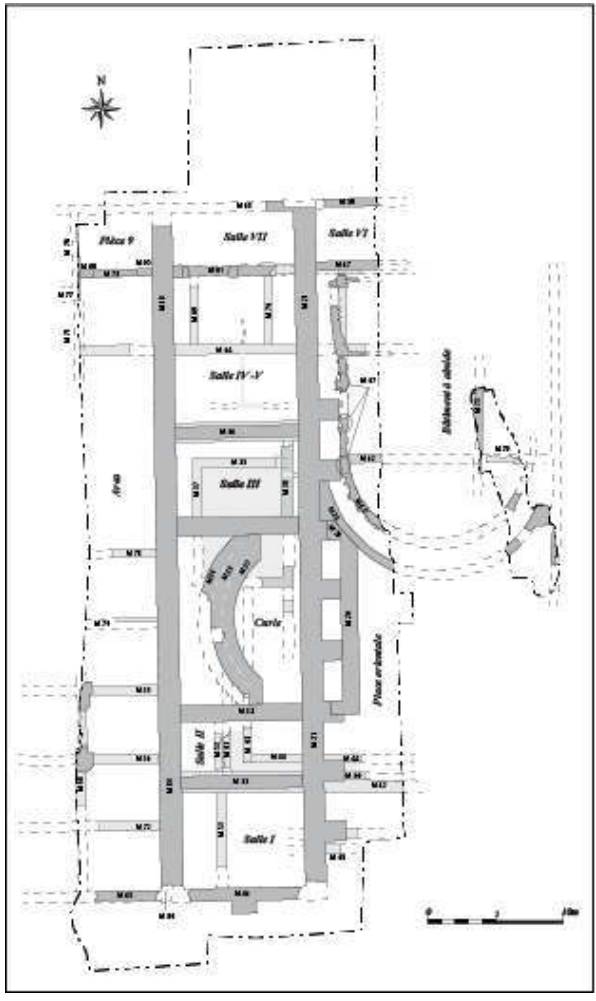

\section{Fig 01}

Plan schématique des édifices, en gris clair l'ensemble thermal ( ${ }^{\text {er }} \mathrm{s}$.), en gris foncé les bâtiments civiques du forum (II ${ }^{\mathrm{e}}-\mathrm{V}^{\mathrm{e}} \mathrm{s}$.)

Plan : J.-Y. Lelièvre (CG 14).

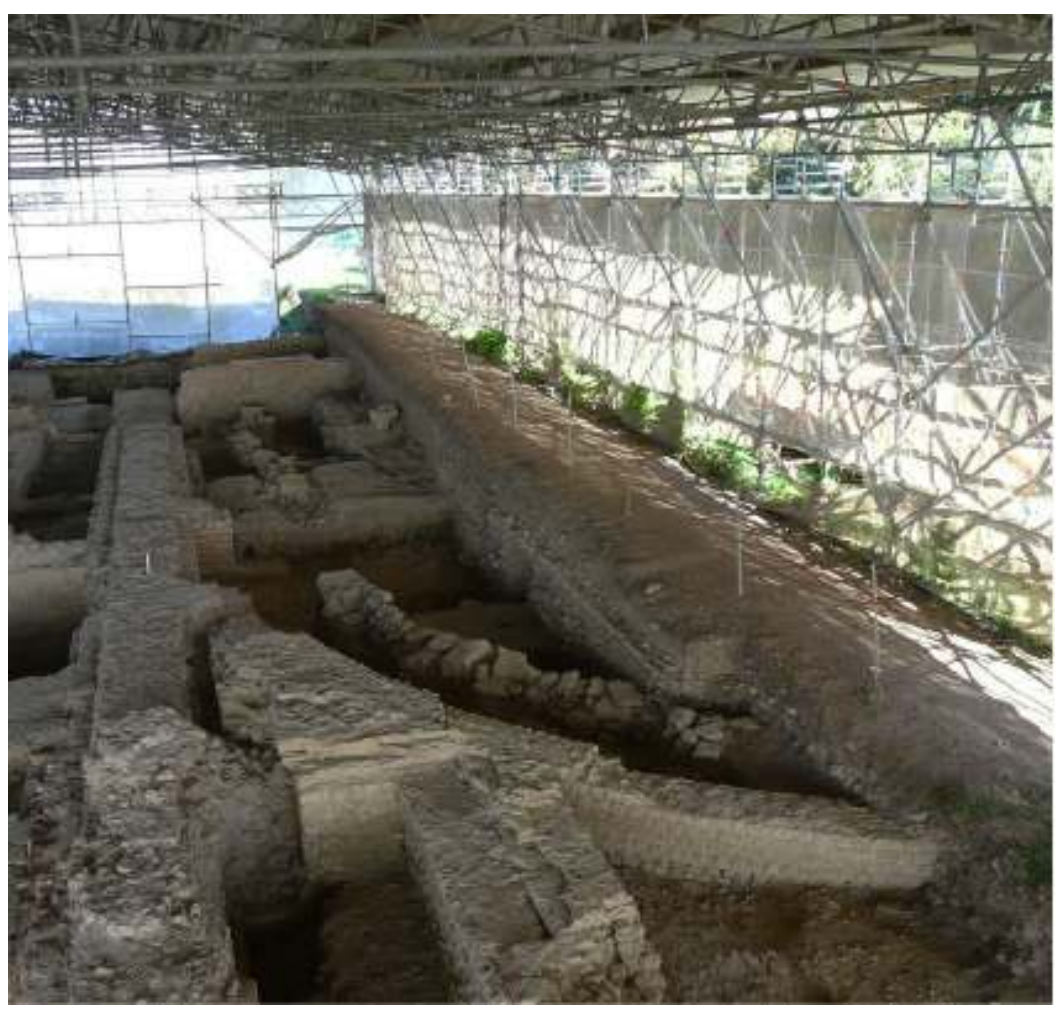




\section{Fig 02}

Vue générale du bâtiment à abside (vue du sud)

Cliché K. Jardel (CG 14)

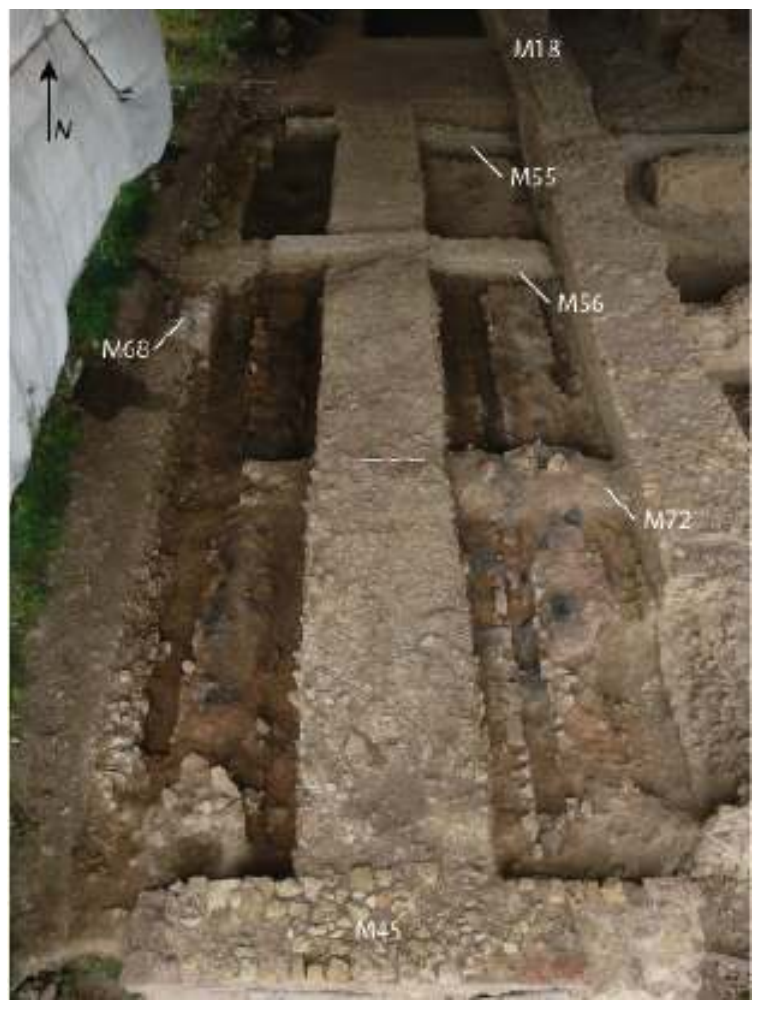

Fig 03

Aménagement d'un plancher de bois

Cliché : P. Mazure (CG 14)

INDEX

Index géographique : Basse-Normandie, Calvados (14), Vieux

Mots-clés : forum, bloc calcaire, colonnade, mur, maçonnerie

Index chronologique : Gallo-romain

operation Fouille programmée (FP)

\section{AUTEURS}

\section{KARINE JARDEL}

CG 14 